\title{
Spatial Organization of Epigenomes
}

\author{
Jonathan Christopher Dubé ${ }^{1}$ Xue Qing David Wang ${ }^{1}$ - Josée Dostie ${ }^{1}$
}

Published online: 4 February 2016

(C) Springer International Publishing AG 2016

\begin{abstract}
The role of genome architecture in transcriptional regulation has become the focus of an increasing number of studies over the past decade. Chromatin organization can have a significant impact on gene expression by promoting or restricting the physical proximity between regulatory DNA elements. Given that any change in chromatin state has the potential to alter DNA folding and the proximity between control elements, the spatial organization of chromatin is inherently linked to its molecular composition. In this review, we explore how modulators of chromatin state and organization might keep gene expression in check. We discuss recent findings and present some of the less well-studied aspects of spatial genome organization such as chromatin dynamics and regulation by non-coding RNAs.
\end{abstract}

Keywords Chromatin organization · Epigenetics ·

Non-coding RNAs · Chromosome conformation capture . Gene expression

This article is part of the Topical Collection on Epigenetics

Josée Dostie

josee.dostie@mcgill.ca

Jonathan Christopher Dubé

christopher.dube@mail.mcgill.ca

Xue Qing David Wang

xue.qing.wang@mail.mcgill.ca

1 Department of Biochemistry and Goodman Cancer Research Center, McGill University, 3655 Promenade Sir-William-Osler, Room 815A, Montréal, Québec, Canada H3G1Y6

\section{Introduction}

\section{Defining Spatial Chromatin Organization}

Over the past decade, the emerging regulatory role of spatial chromatin organization has received much attention, particularly with respect to gene expression [1-4]. The folding of chromosomes and their position in the nuclear space have been studied extensively using a variety of light microscopy techniques [5-7], and more recently in combination with the chromosome conformation capture (3C) technologies $[4,8]$. These techniques remain complementary since visual methods like fluorescence in situ hybridization (FISH) can examine chromatin architecture at the single cell level but are limited to only a few regions, whereas several $3 \mathrm{C}$ technologies can assess spatial organization of entire genomes although across cell populations. However, the perspective gap between the visual and molecular approaches appears to be narrowing with advancements in microscopy $[9,10]$ and probe synthesis that allow visualization of many regions simultaneously [11], and with the realization of a first genomewide 3C-type analysis conducted at the level of single cells $[12 \bullet, 13]$. Even when their limits in scale and scope finally meet, these approaches should always be paired together as some of the data produced by FISH and 3C methods differ $[14,15 \cdot]$. Detailed descriptions of these techniques and their limitations - including how the vast amounts of data they produce can be handled-are described in other reviews [8, 16-19].

Although exactly how and why chromosomes fold in the nucleus remains largely unknown, several key concepts are now well accepted. A number of recent reviews have focused on the spatial organization of mammalian genomes $[4,13,20]$ and thus it will only be discussed in general terms here. For instance, rather than having their chromatin randomly 
arranged in the nuclear space, chromosomes are known to occupy distinct "chromosome territories" (CTs) reflecting preferential interactions between genomic regions located on the same DNA molecule (cis) as opposed to different chromosomes (trans). In addition, CTs themselves are not arbitrarily positioned in the nucleus. Instead, they occupy preferred radial positions from the nuclear center to the periphery with generich chromosomes clustering at the center of the nucleus, while gene-poor CTs tend to reside near the lamina coating the inside of the nuclear envelope [20].

CT analysis with "Hi-C", a variant of the original 3C technique that captures chromatin organization on a genome-wide scale, reveals the existence of two types of "compartments" designated "A" and "B" [21]. Compartments represent multi-megabase genomic regions within chromosomes that preferentially interact with each other. "A" compartments are more transcriptionally active and have a higher GC content than "B" compartments. They are also enriched in open chromatin, genes, and active/poised chromatin marks. "B" compartments are less transcriptionally active, display a stronger propensity for self-association, and are enriched in the repressive H3K9me3 histone mark. Whether compartments exert specific functions or simply reflect the underlying chromatin activity remains unknown. Nonetheless, it is interesting to observe that "B" compartments along chromosomes highly correlate with late replication timing and the position of lamina-associated domains (LADs). These correlations suggest that " $\mathrm{B}$ " compartments might preferentially localize at the nuclear periphery in vivo [22].

At a higher resolution within the compartments are found the "topologically associating domains" (TADs), megabasescale chromatin regions that interact more frequently with themselves than with any other region in the genome [23, 24]. TADs or TAD-like chromatin domains are seen in different organisms including human, mouse, fly, and yeast [23•, 24-26]. Interestingly, many TADs appear conserved across cell types and even between species at syntenic regions. In contrast, the many types of substructures found within TADs (sub-TADs) are much more cell-type specific. These reflect different types of long-range interactions between regulatory DNA elements including promoters, enhancers, and insulators.

Though we are just starting to map chromatin organization across entire genomes $[3,21,23 \cdot, 24,25,27,28]$, it is clear that gene regulation is affected by chromatin architecture [5, 29-35]. The hierarchical model of functional chromatin organization emerging from these studies makes intuitive sense considering all that is involved in transcription and that control elements must first find the gene they regulate in threedimensional (3D) space at specific times under various conditions. Thus, TADs are thought to spatially compartmentalize the linear genome into regulatory units of chromatin where, for example, genes can be regulated independently from their neighbours. This hypothesis is supported by the observation that gene expression patterns within TADs tend to correlate during differentiation [24], and that the activity of a regulatory sensor inserted at several hundred different sites consistently spans large regions correlating with the size and position of TADs [36 $6^{\circ}$.

The idea that TADs partly represent spatial regulatory units of transcription is also supported by the observation of enhancer-promoter contacts mostly within TADs and that displacement of such boundaries may lead to misexpression of genes $[24,37 \bullet]$. Furthermore, removal of TAD boundaries can lead to the spreading of activating histone marks and transcription of genes in the neighbouring TAD [38]. Although these findings support the compartmentalization of genes and regulatory elements into TADs, they do not exclude the possibility of regulatory contacts across TADs. Indeed, the existence of transcription factories suggests some level of interactions between chromatin from different TADs. Transcription factories are specialized nuclear sites where high levels of transcription are detected. They are thought to represent another level of genome compartmentalization driven by co-regulated genes that permit rapid activation of associated genes regardless of their genomic distance [39-41]. Whether or not transcription factories affect the organization of TADs or their position in the nuclear space is unknown.

\section{Chromatin Organization in Single Cells}

Microscopy-based studies clearly demonstrate the inherent dynamic nature of chromatin organization in vivo, even in the nucleus of genotypically and phenotypically identical cell types [42-44]. Given that 3C-based methods yield spatial chromosome maps averaged from millions of cells, new methods are needed to answer questions for which averages no longer suffice. One study pioneered this venture by modifying the Hi-C protocol for contacts within individual $\mathrm{CD} 4^{+}$ $\mathrm{T}_{\mathrm{H}} 1$ cells [12•]. As with the conventional Hi-C method, the existence of CTs and the presence of TADs are observed with single-cell $\mathrm{Hi}-\mathrm{C}$. At the resolution considered, individual chromosomes appear to maintain TAD organization from cell to cell, but contact patterns vary significantly at larger scales and between domains. This single-cell analysis also recapitulates the presence of active domains at CT boundaries. On the other hand, contacts between chromosomes appear at highly distinct regions instead of more uniformly distributed as with the original Hi-C approach, although whether this difference stems from technical biases such as PCR amplification is unclear.

While single-cell analysis methods will be indispensable to fully understand chromosome architecture and its relationship with genomic activities like transcription, developing new sufficiently robust approaches may take some time. Rather than conducting experiments in individual cells followed by genome-wide statistical analyses, alternative approaches such 
as combinatorial cellular indexing might be immediately useful. Combinatorial cellular indexing is a technique involving sequential barcodings and dilutions whereby nuclei can be effectively "compartmentalized" by the barcodes they receive [45]. The power of this technique lies in the fact that singlecell resolution data can be obtained from within cell populations without having to process cells individually. Applying this method to 3C-type datasets might eventually become feasible enough to circumvent the need for novel ultraspecialized methodologies, as is seen for chromatin states in single cells [45].

\section{How Dynamic Is Chromatin Organization?}

Most current techniques thus far can only provide insight into the complexity of chromosome organization at given times without directly informing on the dynamic component. To work around this, one team has compared genome-wide chromatin interactions across multiple cell lineages [46•]. By contrasting chromatin organization in embryonic stem (ES) cells and ES-derived lineages with their respective gene expression and chromatin state, they would uncover cell-type specific changes in spatial organization. Assessing changes in active and inactive states during differentiation may provide a possible mechanism for lineage specification [46•]. They show that while around $36 \%$ of the genome can switch states during differentiation, these changes tend to be restricted to within TADs [46•]. The intra-domain interactions of TADs appear to determine whether a domain is active or inactive, with frequency related to gene expression [46•]. H3K4me1 density appears to be an important predictor of these intra-domain interactions [46 ] — an interesting result given that $\mathrm{H} 3 \mathrm{~K} 4 \mathrm{me} 1$ is often found at poised and/or active enhancers [47, 48], and considering the fact that enhancers exists at many looping sites [49]. Since enhancer density correlates with interaction frequency and $\mathrm{H} 3 \mathrm{~K} 4 \mathrm{me} 1$ associates with enhancers, $\mathrm{H} 3 \mathrm{~K} 4 \mathrm{me} 1$ is thought to help determine interactions during lineage specification through enhancer looping [46•].

An important drawback to comparing cell lineages to infer how chromatin organization contributes to gene expression changes is the difficulty in assessing the actual contribution of architecture to transcription. This relationship can be more clearly examined when systematically tracked over short differentiation time-courses as we previously demonstrated [50•]. Alternatively, we might benefit from models that can at least help us predict chromosome structure and topology. In the past, we have seen the success of energy models in determining protein structure [51-53]. However, unlike most folded proteins, which tend to prefer their equilibrium state $[54,55]$, DNA is large enough to prevent itself from reaching its low energy state [56]. Further complications include the numerous proteins and DNA elements, which determine contacts as well as variations between cell types and cell cycle phases [56].

To get around this, one study proposes an entropy approach with interesting results [56]. They show that the relaxed interphase chromatin landscape could be simulated, complete with contact probabilities. They also recapitulate topology and indicate that TADs minimize knots of chromatin and might allow discrete unfolding to occur. Although further modeling of the different stages of the cell cycle will be possible as contact maps become available, a limitation is that this approach only presents ideal conformations. Nevertheless, a model that mimics how dynamic structure/conformation relates to gene function will help us better understand gene regulation [56].

\section{How Modulators of Chromatin State and Organization Might Keep Gene Expression in Check}

Overall genome architecture is guided by chromatin interactions with nuclear landmarks like the lamina as well as by intra- and inter-chromosomal contacts mediated by chromatin-binding proteins (Fig. 1). As such, chromosome organization is inherently linked to chromatin state, and any change to its composition has the potential to alter folding and the proximity between regulatory DNA elements. Chromatin composition can be altered through various pathways, including the more stable epigenetic types like DNA and histone modifications. Epigenetic regulation is central to all aspects of human life including development, health, and disease. These mechanisms modify gene expression and can have a significant impact on genome architecture. By mutually affecting each other, chromatin state and architecture may take part in a self-enforcing feedback process to propagate cell-fate memory [57].

The importance of spatial genome organization in human disease is clearly demonstrated in cancers where single nucleotide polymorphisms (SNPs) are found to create novel enhancers acting long-range to activate distal genes through intra-chromosomal contacts and chromatin looping [58-60]. Improper binding to nuclear landmarks is also linked to human disease. For example, studies on laminopathies like Emery-Dreifuss muscular dystrophy demonstrate that this disease can originate from mutations in a lamin protein, which specifically causes abnormal retention and silencing of muscle-specific genes at the nuclear envelope [61]. A particularly interesting group of proteins likely to contribute to these changes are the polycomb group $(\mathrm{PcG})$ proteins. PcG proteins play an essential role during differentiation by repressing key developmental genes until their appropriate time of expression. Importantly, they are modulators of stem cell differentiation that can be deregulated in cancers.

PcG proteins are part of two distinct complexes called $\mathrm{PRC} 1$ and PRC2. These complexes repress transcription and have distinct enzymatic activities. While PRC1 catalyzes the 


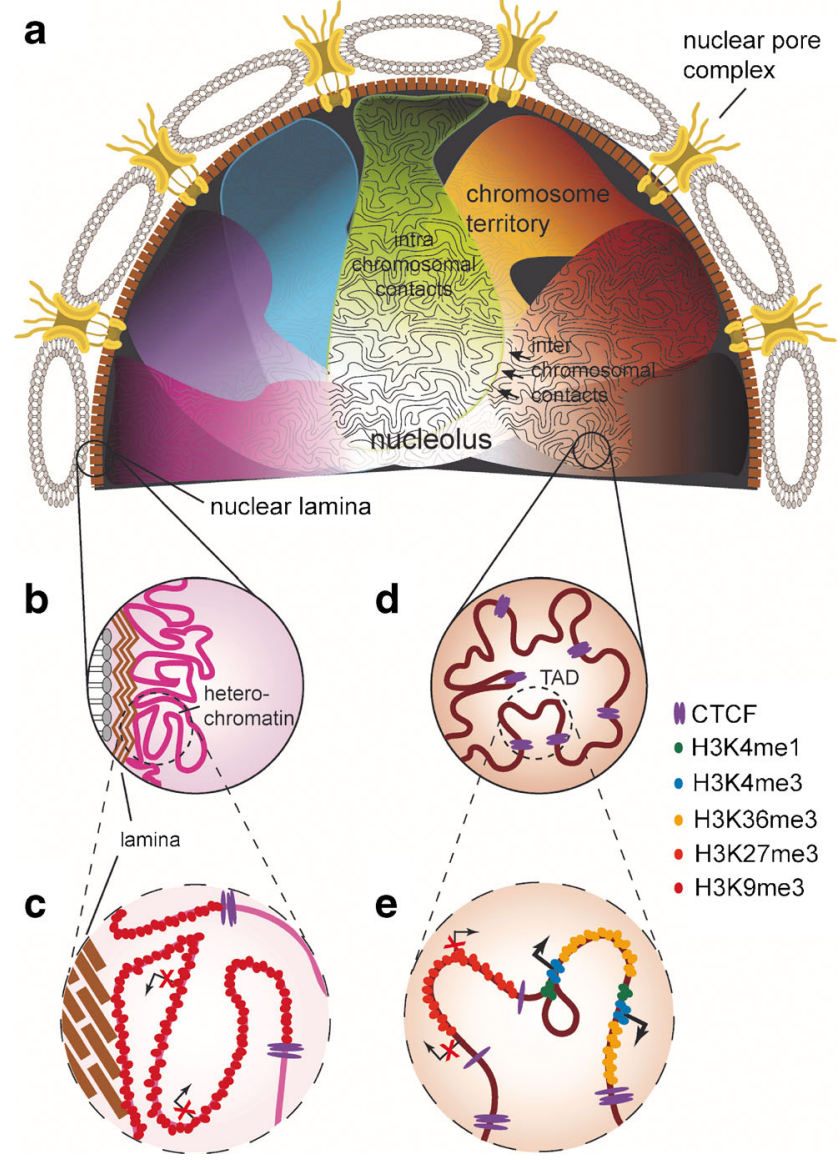

Fig. 1 Genome architecture is guided by contacts with nuclear landmarks, and by intra- and inter-chromosomal interactions mediated by chromatin-binding proteins. a Schematic representation of a mammalian nucleus illustrating how chromosome territories (CTs) can relate to each other and with respect to the nuclear lamina (brown dashed line). Darker areas within CTs represent heterochromatic regions near the lamina. The nucleolus is highlighted in white. The lines within CTs represent contacts within (intra) and between (inter) chromosomes. Arrows point to inter-chromosomal contacts. b Lamina-associating domain (LAD) showing heterochromatin clustered near the nuclear lamins. c Close-up indicating silencing marks (H3K9me3) with CTCF at the borders of LADs. d Topologically associating domain (TAD) showing regions defined by CTCF boundary elements at the megabase level. e Close-up demonstrating sub-TADs within TADs can be differentially regulated. Chromatin can either be repressed (H3K27me3) or actively transcribed (H3K36me3). $\mathrm{H} 3 \mathrm{~K} 4$ methylation is seen at active promoters (H3K4me3) and enhancers (H3K4me1)

mono-ubiquitination of H2A on lysine 119 (H2AK119Ub1), PRC2 catalyzes the di- and tri-methylation of $\mathrm{H} 3$ on lysine 27 (H3K27me2/3) [62-64]. Genetic and biochemical studies show that PRCs control transcription in pluripotent cells by catalytic and non-catalytic mechanisms $\left[65,660^{\circ}\right.$. They are shown to induce chromatin compaction $[65,66 \bullet, 67]$, but can also form long-range contacts within and between chromosomes in vivo, supporting their potential role in regulating gene expression through genome architecture. For example, deletion of a PRC2 subunit that leads to H3K27me2/3 depletion correlates with chromatin decompaction at $\mathrm{HOX}$ loci as detected by FISH [66 ${ }^{\bullet}$. H2A ubiquitinylation is also lost under these conditions since PRC1 recruitment requires PRC2 [68]. Interestingly, chromatin decompaction also occurs in cells where the PRC1 ubiquitinase subunit Ring1B is deleted, even though $\mathrm{H} 3 \mathrm{~K} 27 \mathrm{me} 2 / 3$ levels are maintained [66•]. Since complementation of Ring $1 B$-/- cells with either wild-type protein or a catalytically dead mutant (I53A) restore compaction at $\mathrm{HOX}$ loci by FISH [66•], Ring1B can likely mediate longrange contacts in a non-catalytic manner.

As indicated by the example of muscle-specific gene silencing described above, directing chromatin regions to the nuclear lamina can have a significant impact on gene expression. Genomic regions naturally targeted to the nuclear lamina are termed LADs and the genes contained within them are mostly repressed [69-71]. LADs are enriched in the H3K9me2/3 silencing marks, while their borders also contain H3K27me3 and CTCF binding sites [35, 71-73]. CTCF (CCCTC-binding factor) is viewed as a key factor in genome organization [1]. It can act as an insulator/barrier at heterochromatin boundaries and divide chromatin into silent and active domains. It is enriched at TAD boundaries and can also mediate long-range chromatin interactions such as those observed during enhancer-promoter looping.

Genomic regions associated with the nuclear lamina can be regulated as shown for developmentally regulated variable LADs (vLADs). vLAD borders appear to be critical for their dynamic association with the lamina, and are enriched for YY1 binding sites [74•]. That YY1 plays a role in this process agrees with previous studies demonstrating the recruitment of PRC2 by YY1 [75-82]. Accordingly, chromatin repositioning to the nuclear lamina is dependent on YY1 and H3K27me3 enrichment at LADs, in addition to H3K9me2/3 [74•, 83-85].

Recently, we have reported a link between CTCF-CTCF interactions, $\mathrm{PcG}$ silencing, and 3D chromatin organization [50•]. In human and mouse cells, the HOXA cluster is divided between two TADs with $3^{\prime}$ genes residing into one TAD and those at the $5^{\prime}$ end extending into the other. Like most TAD boundaries, the HOXA middle region is enriched in sites bound by CTCF [50•]. We show that silencing by $\mathrm{PcG}$ is associated with the reconfiguration of CTCF-CTCF contacts at the HOXA TAD boundary, which induces a kink upon differentiation. Our results support a model whereby regulated looping between CTCF-bound sites at TAD boundaries might control the folding path of chromatin, the proximity between TADs, the formation of contacts between them, and thereby the topology of genomes.

\section{Non-Coding RNAs as Modulators of Chromatin State and Organization}

Another mechanism by which $\mathrm{PcG}$ proteins regulate genome architecture is through long non-coding RNAs (lncRNAs) [86]. Over the last decade, advances in high-throughput 
sequencing technology have fuelled interest in mapping the transcriptome of eukaryotic cells. These studies have revealed thousands of non-coding RNAs throughout mouse and human genomes [87, 88], which are now classified based primarily on their length and origin of transcription. Long non-coding RNAs represent the broadest class of these molecules described to be at least $200 \mathrm{nts}$ in length with little to no protein-coding potential [89]. Additional categories such as long intergenic non-coding RNAs (lincRNAs) and enhancer RNAs (eRNAs) are more descriptive nomenclatures based on the site of origin.

Despite being largely transcribed by RNA polymerase II and having post-transcriptional processing similar to mRNAs, lncRNAs appear poorly conserved between species [90]. This observation led to early skepticism as to whether or not lncRNAs possess any relevant function in the cell. Numerous studies of individual lncRNAs now show that they play important roles in regulating gene expression. These transcripts adopt a variety of mechanisms by which they can affect their target genes. Most notably, they associate with histone modifying complexes and direct changes to the chromatin state of their targets. For example, the lncRNA transcripts Air and kcnqlot 1 play important roles in gene imprinting by recruiting PRC2 and G9a complexes to their target regions on the paternal allele for silencing by methylating H3K27 and H3K9, respectively [91, 92]. These lncRNAs act in cis, contrary to the IncRNA HOTAIR which regulates gene expression across different chromosomes (trans) [93]. Transcribed from the HOXC locus, HOTAIR recruits both PRC2 and the histone H3K4me2 demethylase LSD1 to supress gene expression at the HOXD locus [93-95]. By serving as a scaffold for different histone modifying complexes, HOTAIR shows that IncRNAs can direct a variety of changes to the chromatin state of their target genes.

A role for IncRNA in mediating trans-chromosomal interactions is seen with the lncRNA FIRRE. RNA antisense purification (RAP) and FISH experiments show FIRRE localizing near its site of transcription and bridging both cis and trans chromosomal interactions to that region [96]. Interestingly, the maintenance of these inter-chromosomal interactions requires both the lncRNA and its associated protein component hnRNPU. This is particularly interesting as hnRNPU is essential for localizing XIST to an X chromosome for silencing [97].

While numerous IncRNAs interact with histone-modifying complexes to regulate gene expression, much less is known about their role in regulating $3 \mathrm{D}$ chromatin architecture. A recent study shows that the lncRNA XIST, responsible for Xchromosome inactivation in female mammalian cells, also plays a role in the chromatin organization of the inactive $\mathrm{X}$ chromosome (Xi) [98•]. XIST is a 17-kb long lncRNA transcribed from the $\mathrm{X}$ chromosome, which recruits PRC2 for suppression [99]. Further investigations identified several additional proteins that interact with XIST such as the ATRX
RNA helicase, YY1, and hnRNPU [97, 100, 101]. Each of these components plays an important role in maintaining XIST interaction with PRC2 or tethering the complex to the X chromosome itself. Recently, analysis of the XIST interactome revealed over 80 proteins associating with the lncRNA, including CTCF and members of the cohesin complex (SMC1A, SMC2, and RAD21), which are known to regulate 3D chromatin architecture [98•]. Xi does not have any of the TADs present in the active $\mathrm{X}$ chromosome $(\mathrm{Xa})$ and is organized instead into megadomains. However, upon removal of XIST, the chromatin architecture of Xi reverts to that of Xa with cohesin demarking the boundaries of reformed TADs [98•]. This suggests that XIST plays a direct role in shaping chromatin architecture by actively preventing the formation of TADs on $\mathrm{Xi}$.

These findings open a new field in epigenomics for IncRNA-mediated chromatin organization. As these transcripts are often long, likely possessing highly-folded structures, they may serve as docking sites for a wide variety of proteins involved in nuclear architecture. This may permit the directed localization of these components and therefore could affect both intra- and inter-chromosomal interactions.

\section{Conclusions and Perspectives}

Microscopy-based studies and those using 3C-type technologies have altogether led to the current model of genome architecture wherein chromosomes are organized in hierarchical length scales [4]. From high to low resolution, genomic DNA wrapping around histone octamers forming nucleosomes represents the first level of genome organization in this model. By engaging in long-range cis contacts, chromatin fibers fold into substructures (sub-TADs), with topologies varying in a tissue-specific manner [27]. These conformations exist within larger megabase-sized chromatin domains, the TADs, which in contrast appear largely conserved between cell types and across species. TADs contained within compartments "A" (open/active) or "B" (closed/silent) interact together within their respective chromosome territories. The nuclear position of CTs is not random but rather defined at least in part by transcriptional activity and interactions with nuclear landmarks like the nucleoli and lamina through heterochromatic regions.

Although compelling, this model does not answer many pressing questions about genome organization, including why and how this folding occurs, the relationship between each folding state, and how changes at one level may impact the conformation and position of chromosomes within the nucleus. Also, despite the existence of many robust and complementary technologies, the field would nonetheless benefit highly from new approaches that capture chromatin organization along with transcriptional and epigenomic changes in 
real-time and preferably at the level of single cells - a tall order not likely to be reached anytime soon. Regardless of whether it will come through the development of new methodologies to probe chromatin organization or through computational/mathematical modeling of population-based datasets, understanding the actual relationship between chromatin architecture and state will be essential to appreciate the natural plasticity of chromatin and identify conformation patterns that lead to improper gene expression and disease. In this respect, chromatin organization is often altered in human diseases such as cancer [102], and we have recently provided evidence of its value as a discovery tool for candidate cancer biomarkers [103•]. It will be interesting to see whether chromatin conformations actually represent ideal biomarkers and to define the value of such signatures in the clinic [104].

\section{Compliance with Ethical Standards}

Conflict of Interest Jonathan Christopher Dubé, Xue Qing David Wang, and Josée Dostie declare that they have no conflict of interest.

Human and Animal Rights and Informed Consent This article does not contain any studies with human or animal subjects performed by any of the authors.

\section{References}

Papers of particular interest, published recently, have been highlighted as:

- Of importance

1. Phillips JE, Corces VG. CTCF: master weaver of the genome. Cell. 2009;137(7):1194-211. doi:10.1016/j.cell.2009.06.001.

2. Smallwood A, Ren B. Genome organization and long-range regulation of gene expression by enhancers. Curr Opin Cell Biol. 2013;25(3):387-94. doi:10.1016/j.ceb.2013.02.005.

3. Gorkin DU, Leung D, Ren B. The 3D genome in transcriptional regulation and pluripotency. Cell Stem Cell. 2014;14(6):762-75. doi:10.1016/j.stem.2014.05.017.

4. Fraser J, Williamson I, Bickmore WA, Dostie J. An overview of genome organization and how we got there: from FISH to Hi-C. Microbiol Mol Biol Rev: MMBR. 2015;79(3):347-72. doi:10. 1128/MMBR.00006-15.

5. Cremer M, von Hase J, Volm T, Brero A, Kreth G, Walter J, et al. Non-random radial higher-order chromatin arrangements in nuclei of diploid human cells. Chromosome Res. 2001;9(7):541-67. doi: 10.1023/A:1012495201697.

6. Bolzer A, Kreth G, Solovei I, Koehler D, Saracoglu K, Fauth C, et al. Three-dimensional maps of all chromosomes in human male fibroblast nuclei and prometaphase rosettes. PLoS Biol. 2005;3(5), e157. doi:10.1371/journal.pbio.0030157.

7. Kupper K, Kolbl A, Biener D, Dittrich S, von Hase J, Thormeyer $\mathrm{T}$, et al. Radial chromatin positioning is shaped by local gene density, not by gene expression. Chromosoma. 2007;116(3): 285-306. doi:10.1007/s00412-007-0098-4.
8. Ethier SD, Miura H, Dostie J. Discovering genome regulation with $3 \mathrm{C}$ and $3 \mathrm{C}$-related technologies. Biochim Biophys Acta. 2012;1819(5):401-10. doi:10.1016/j.bbagrm.2011.12.004.

9. Lakadamyali M, Cosma MP. Advanced microscopy methods for visualizing chromatin structure. FEBS Lett. 2015. doi:10.1016/j. febslet.2015.04.012.

10. Ricci MA, Manzo C, Garcia-Parajo MF, Lakadamyali M, Cosma MP. Chromatin fibers are formed by heterogeneous groups of nucleosomes in vivo. Cell. 2015;160(6):1145-58. doi:10.1016/j. cell.2015.01.054.

11. Boyle S, Rodesch MJ, Halvensleben HA, Jeddeloh JA, Bickmore WA. Fluorescence in situ hybridization with high-complexity repeat-free oligonucleotide probes generated by massively parallel synthesis. Chromosome Res. 2011;19(7):901-9. doi:10.1007/ s10577-011-9245-0.

12. Nagano T, Lubling Y, Stevens TJ, Schoenfelder S, Yaffe E, Dean $\mathrm{W}$, et al. Single-cell Hi-C reveals cell-to-cell variability in chromosome structure. Nature. 2013;502(7469):59-64. doi:10.1038/ nature12593. First description of a Hi-C analysis at the single cell level.

13. Furlan-Magaril M, Varnai C, Nagano T, Fraser P. 3D genome architecture from populations to single cells. Curr Opin Genet Dev. 2015;31:36-41. doi:10.1016/j.gde.2015.04.004.

14. Dostie J, Bickmore WA. Chromosome organization in the nucleus - charting new territory across the Hi-Cs. Curr Opin Genet Dev. 2012;22(2):125-31. doi:10.1016/j.gde.2011.12.006.

15. Williamson I, Berlivet S, Eskeland R, Boyle S, Illingworth RS, Paquette D, et al. Spatial genome organization: contrasting views from chromosome conformation capture and fluorescence in situ hybridization. Genes Dev. 2014;28(24):2778-91. doi:10.1101/ gad.251694.114. Provides compelling evidence of the complementarity of the visual and molecular techniques used in the study of genome architecture.

16. Dostie J, Zhan Y, Dekker J. Chromosome conformation capture carbon copy technology. Curr Protoc Mol Biol. 2007; Chapter 21(Unit 21.14).

17. Ferraiuolo MA, Sanyal A, Naumova N, Dekker J, Dostie J. From cells to chromatin: capturing snapshots of genome organization with 5C technology. Methods. 2012;58(3):255-67. doi:10.1016/ j.ymeth.2012.10.011.

18. Dekker J, Marti-Renom MA, Mirny LA. Exploring the threedimensional organization of genomes: interpreting chromatin interaction data. Nat Rev Genet. 2013;14(6):390-403. doi:10.1038/ $\operatorname{nrg} 3454$.

19. Mattout A, Cabianca DS, Gasser SM. Chromatin states and nuclear organization in development - a view from the nuclear lamina. Genome Biol. 2015;16:174. doi:10.1186/s13059-015-0747-5.

20. Bickmore WA. The spatial organization of the human genome. Annu Rev Genomics Hum Genet. 2013;14:67-84. doi:10.1146/ annurev-genom-091212-153515.

21. Lieberman-Aiden E, van Berkum NL, Williams L, Imakaev M, Ragoczy T, Telling A, et al. Comprehensive mapping of longrange interactions reveals folding principles of the human genome. Science. 2009;326(5950):289-93. doi:10.1126/science.1181369.

22. Ryba T, Hiratani I, Lu J, Itoh M, Kulik M, Zhang J, et al. Evolutionarily conserved replication timing profiles predict long-range chromatin interactions and distinguish closely related cell types. Genome Res. 2010;20(6):761-70. doi:10.1101/gr. 099655.109.

23. Dixon JR, Selvaraj S, Yue F, Kim A, Li Y, Shen Y, et al. Topological domains in mammalian genomes identified by analysis of chromatin interactions. Nature. 2012;485(7398):376-80. doi:10.1038/nature11082. Reports the existence of TADs for the first time.

24. Nora EP, Lajoie BR, Schulz EG, Giorgetti L, Okamoto I, Servant N, et al. Spatial partitioning of the regulatory landscape 
of the X-inactivation centre. Nature. 2012;485(7398):381-5. doi: 10.1038/nature11049.

25. Sexton T, Yaffe E, Kenigsberg E, Bantignies F, Leblanc B, Hoichman M, et al. Three-dimensional folding and functional organization principles of the Drosophila genome. Cell. 2012;148(3):458-72. doi:10.1016/j.cell.2012.01.010.

26. Hsieh TH, Weiner A, Lajoie B, Dekker J, Friedman N, Rando OJ. Mapping nucleosome resolution chromosome folding in yeast by Micro-C. Cell. 2015;162(1):108-19. doi:10.1016/j.cell.2015.05. 048 .

27. Phillips-Cremins JE, Sauria ME, Sanyal A, Gerasimova TI, Lajoie BR, Bell JS, et al. Architectural protein subclasses shape 3D organization of genomes during lineage commitment. Cell. 2013;153(6):1281-95. doi:10.1016/j.cell.2013.04.053.

28. Rao SS, Huntley MH, Durand NC, Stamenova EK, Bochkov ID, Robinson JT, et al. A 3D map of the human genome at kilobase resolution reveals principles of chromatin looping. Cell. 2014;159(7):1665-80. doi:10.1016/j.cell.2014.11.021.

29. Misteli T. Concepts in nuclear architecture. Bioessays. 2005;27(5):477-87. doi:10.1002/bies.20226.

30. Scaffidi P, Misteli T. Lamin A-dependent nuclear defects in human aging. Science. 2006;312(5776):1059-63. doi:10.1126/science. 1127168.

31. Cremer T, Cremer M, Dietzel S, Muller S, Solovei I, Fakan S. Chromosome territories - a functional nuclear landscape. Curr Opin Cell Biol. 2006;18(3):307-16. doi:10.1016/j.ceb.2006.04. 007.

32. Fedorova E, Zink D. Nuclear architecture and gene regulation. Biochim Biophys Acta. 2008;1783(11):2174-84. doi:10.1016/j. bbamcr.2008.07.018.

33. Elcock LS, Bridger JM. Exploring the relationship between interphase gene positioning, transcriptional regulation and the nuclear matrix. Biochem Soc Trans. 2010;38(Pt 1):263-7. doi:10.1042/ BST0380263.

34. Ferrai C, de Castro IJ, Lavitas L, Chotalia M, Pombo A. Gene positioning. Cold Spring Harb Perspect Biol. 2010;2(6):a000588. doi:10.1101/cshperspect.a000588.

35. Van Bortle K, Corces VG. Nuclear organization and genome function. Annu Rev Cell Dev Biol. 2012;28:163-87. doi:10.1146/ annurev-cellbio-101011-155824.

36. Symmons O, Uslu VV, Tsujimura T, Ruf S, Nassari S, Schwarzer $\mathrm{W}$, et al. Functional and topological characteristics of mammalian regulatory domains. Genome Res. 2014;24(3):390-400. doi:10. $1101 /$ gr.163519.113. Provides compelling evidence that enhancer activity is mostly restricted to their respective TADs.

37. Lupianez DG, Kraft K, Heinrich V, Krawitz P, Brancati F, Klopocki E, et al. Disruptions of topological chromatin domains cause pathogenic rewiring of gene-enhancer interactions. Cell. 2015;161(5):25. doi:10.1016/j.cell.2015.04.004. Demonstrates the importance of TAD organization with respect to human health.

38. Narendra V, Rocha PP, An D, Raviram R, Skok JA, Mazzoni EO, et al. Transcription. CTCF establishes discrete functional chromatin domains at the Hox clusters during differentiation. Science. 2015;347(6225):1017-21. doi:10.1126/science.1262088.

39. Larkin JD, Papantonis A, Cook PR. Promoter type influences transcriptional topography by targeting genes to distinct nucleoplasmic sites. J Cell Sci. 2013;126(Pt 9):2052-9. doi:10.1242/jcs. 123653

40. Larkin JD, Papantonis A, Cook PR, Marenduzzo D. Space exploration by the promoter of a long human gene during one transcription cycle. Nucleic Acids Res. 2013;41(4):2216-27. doi:10.1093/ nar/gks1441.

41. Papantonis A, Kohro T, Baboo S, Larkin JD, Deng B, Short P, et al. TNFalpha signals through specialized factories where responsive coding and miRNA genes are transcribed. EMBO J. 2012;31(23):4404-14. doi:10.1038/emboj.2012.288.

42. Osborne CS, Chakalova L, Brown KE, Carter D, Horton A, Debrand E, et al. Active genes dynamically colocalize to shared sites of ongoing transcription. Nat Genet. 2004;36(10):1065-71. doi:10.1038/ng1423.

43. Schoenfelder S, Sexton T, Chakalova L, Cope NF, Horton A, Andrews S, et al. Preferential associations between co-regulated genes reveal a transcriptional interactome in erythroid cells. Nat Genet. 2010;42(1):53-61. doi:10.1038/ng.496.

44. Rapkin LM, Anchel DR, Li R, Bazett-Jones DP. A view of the chromatin landscape. Micron. 2012;43(2-3):150-8. doi:10.1016/j. micron.2011.11.007.

45. Cusanovich DA, Daza R, Adey A, Pliner HA, Christiansen L, Gunderson KL, et al. Multiplex single-cell profiling of chromatin accessibility by combinatorial cellular indexing. Science. 2015;348(6237):910-4. doi:10.1126/science.aab1601.

46. Dixon JR, Jung I, Selvaraj S, Shen Y, Antosiewicz-Bourget JE, Lee AY, et al. Chromatin architecture reorganization during stem cell differentiation. Nature. 2015;518(7539):331-6. doi:10.1038/ nature 14222. Provides evidence that H3K4me1 might represent a driver of chromatin conformation changes during differentiation.

47. Heintzman ND, Stuart RK, Hon G, Fu Y, Ching CW, Hawkins $\mathrm{RD}$, et al. Distinct and predictive chromatin signatures of transcriptional promoters and enhancers in the human genome. Nat Genet. 2007;39(3):311-8. doi:10.1038/ng1966.

48. Heintzman ND, Hon GC, Hawkins RD, Kheradpour P, Stark A, Harp LF, et al. Histone modifications at human enhancers reflect global cell-type-specific gene expression. Nature. 2009;459(7243):108-12. doi:10.1038/nature07829.

49. Sanyal A, Lajoie BR, Jain G, Dekker J. The long-range interaction landscape of gene promoters. Nature. 2012;489(7414):109-13. doi:10.1038/nature11279.

50. Rousseau M, Crutchley JL, Miura H, Suderman M, Blanchette M, Dostie J. Hox in motion: tracking HoxA cluster conformation during differentiation. Nucleic Acids Res. 2014;42(3):1524-40. doi:10.1093/nar/gkt998. First evidence that PcG silencing near a TAD boundary might influence the chromatin folding path at the boundary by modulating the pattern of CTCF-CTCF interactions.

51. Bryngelson JD, Onuchic JN, Socci ND, Wolynes PG. Funnels, pathways, and the energy landscape of protein folding: a synthesis. Proteins. 1995;21(3):167-95. doi:10.1002/prot.340210302.

52. Frauenfelder H, Sligar SG, Wolynes PG. The energy landscapes and motions of proteins. Science. 1991;254(5038):1598-603. doi: 10.1126/science.1749933.

53. Wolynes PG. Evolution, energy landscapes and the paradoxes of protein folding. Biochimie. 2014. doi:10.1016/j.biochi.2014.12. 007.

54. Grosberg A, Rabin Y, Havlin S, Neer A. Crumpled globule model of the three-dimensional structure of DNA. Europhys Lett. 1993;23(5):373-8. doi:10.1209/0295-5075/23/5/012.

55. Rosa A, Everaers R. Structure and dynamics of interphase chromosomes. PLoS Comput Biol. 2008;4(8), e1000153. doi:10.1371/ journal.pcbi.1000153.

56. Zhang B, Wolynes PG. Topology, structures, and energy landscapes of human chromosomes. Proc Natl Acad Sci U S A. 2015;112(19):6062-7. doi:10.1073/pnas.1506257112.

57. Cavalli G, Misteli T. Functional implications of genome topology. Nat Struct Mol Biol. 2013;20(3):290-9. doi:10.1038/nsmb.2474.

58. Pomerantz MM, Ahmadiyeh N, Jia L, Herman P, Verzi MP, Doddapaneni H, et al. The 8q24 cancer risk variant rs6983267 shows long-range interaction with MYC in colorectal cancer. Nat Genet. 2009;41(8):882-4. doi:10.1038/ng.403. 
59. Pittman AM, Naranjo S, Jalava SE, Twiss P, Ma Y, Olver B, et al. Allelic variation at the $8 \mathrm{q} 23.3$ colorectal cancer risk locus functions as a cis-acting regulator of EIF3H. PLoS Genet. 2010;6(9), e1001126. doi:10.1371/journal.pgen.1001126.

60. Meyer KB, Maia AT, O’Reilly M, Ghoussaini M, Prathalingam R, Porter-Gill P, et al. A functional variant at a prostate cancer predisposition locus at 8q24 is associated with PVT1 expression. PLoS Genet. 2011;7(7), e1002165. doi:10.1371/journal.pgen. 1002165.

61. Mattout A, Pike BL, Towbin BD, Bank EM, Gonzalez-Sandoval A, Stadler MB, et al. An EDMD mutation in C. elegans lamin blocks muscle-specific gene relocation and compromises muscle integrity. Curr Biol. 2011;21(19):1603-14. doi:10.1016/j.cub. 2011.08.030.

62. de Napoles M, Mermoud JE, Wakao R, Tang YA, Endoh M, Appanah R, et al. Polycomb group proteins Ring1A/B link ubiquitylation of histone $\mathrm{H} 2 \mathrm{~A}$ to heritable gene silencing and $\mathrm{X}$ inactivation. Dev Cell. 2004;7(5):663-76. doi:10.1016/j.devcel. 2004.10.005.

63. Cao R, Wang L, Wang H, Xia L, Erdjument-Bromage H, Tempst $\mathrm{P}$, et al. Role of histone H3 lysine 27 methylation in polycombgroup silencing. Science. 2002;298(5595):1039-43. doi:10.1126/ science. 1076997.

64. Wang L, Brown JL, Cao R, Zhang Y, Kassis JA, Jones RS. Hierarchical recruitment of polycomb group silencing complexes. Mol Cell. 2004;14(5):637-46. doi:10.1016/j.molcel.2004.05.009.

65. Francis NJ, Kingston RE, Woodcock CL. Chromatin compaction by a polycomb group protein complex. Science. 2004;306(5701): 1574-7. doi:10.1126/science.1100576.

66. Eskeland R, Leeb M, Grimes GR, Kress C, Boyle S, Sproul D, et al. Ring1B compacts chromatin structure and represses gene expression independent of histone ubiquitination. Mol Cell. $2010 ; 38(3): 452-64$. doi:10.1016/j.molcel.2010.02.032. Compelling evidence that Ring1B mediates long-range chromatin looping in a non-catalytic manner.

67. Tiwari VK, Cope L, McGarvey KM, Ohm JE, Baylin SB. A novel 6C assay uncovers polycomb-mediated higher order chromatin conformations. Genome Res. 2008;18(7):1171-9. doi:10.1101/ gr.073452.107.

68. $\mathrm{Ku} \mathrm{M}$, Koche RP, Rheinbay E, Mendenhall EM, Endoh M, Mikkelsen TS, et al. Genomewide analysis of PRC1 and PRC2 occupancy identifies two classes of bivalent domains. PLoS Genet. 2008;4(10), e1000242. doi:10.1371/journal.pgen. 1000242.

69. Finlan LE, Sproul D, Thomson I, Boyle S, Kerr E, Perry P, et al. Recruitment to the nuclear periphery can alter expression of genes in human cells. PLoS Genet. 2008;4(3), e1000039. doi:10.1371/ journal.pgen.1000039.

70. Reddy KL, Zullo JM, Bertolino E, Singh H. Transcriptional repression mediated by repositioning of genes to the nuclear lamina. Nature. 2008;452(7184):243-7. doi:10.1038/nature06727.

71. Zullo JM, Demarco IA, Pique-Regi R, Gaffney DJ, Epstein CB, Spooner CJ, et al. DNA sequence-dependent compartmentalization and silencing of chromatin at the nuclear lamina. Cell. 2012;149(7):1474-87. doi:10.1016/j.cell.2012.04.035.

72. Guelen L, Pagie L, Brasset E, Meuleman W, Faza MB, Talhout W, et al. Domain organization of human chromosomes revealed by mapping of nuclear lamina interactions. Nature. 2008;453(7197): 948-51. doi:10.1038/nature06947.

73. Meuleman W, Peric-Hupkes D, Kind J, Beaudry JB, Pagie L, Kellis M, et al. Constitutive nuclear lamina-genome interactions are highly conserved and associated with A/T-rich sequence. Genome Res. 2013;23(2):270-80. doi:10.1101/gr.141028.112.

74. Harr JC, Luperchio TR, Wong X, Cohen E, Wheelan SJ, Reddy $\mathrm{KL}$. Directed targeting of chromatin to the nuclear lamina is mediated by chromatin state and A-type lamins. J Cell Biol.
2015;208(1):33-52. doi:10.1083/jcb.201405110. Compelling demonstration that YY1 binding at LAD boundaries is important for dynamic association with the nuclear lamina.

75. Satijn DP, Hamer KM, den Blaauwen J, Otte AP. The polycomb group protein EED interacts with YY1, and both proteins induce neural tissue in Xenopus embryos. Mol Cell Biol. 2001;21(4): 1360-9. doi:10.1128/MCB.21.4.1360-1369.2001.

76. Atchison L, Ghias A, Wilkinson F, Bonini N, Atchison ML. Transcription factor YY1 functions as a $\mathrm{PcG}$ protein in vivo. EMBO J. 2003;22(6):1347-58. doi:10.1093/emboj/cdg124.

77. Caretti G, Di Padova M, Micales B, Lyons GE, Sartorelli V. The Polycomb Ezh2 methyltransferase regulates muscle gene expression and skeletal muscle differentiation. Genes Dev. 2004;18(21): 2627-38. doi:10.1101/gad.1241904.

78. Srinivasan L, Atchison ML. YY1 DNA binding and PcG recruitment requires CtBP. Genes Dev. 2004;18(21):2596-601. doi:10. 1101/gad.1228204.

79. Liu H, Schmidt-Supprian M, Shi Y, Hobeika E, Barteneva N, Jumaa H, et al. Yin Yang 1 is a critical regulator of B-cell development. Genes Dev. 2007;21(10):1179-89. doi:10.1101/gad. 1529307.

80. O'Meara MM, Simon JA. Inner workings and regulatory inputs that control Polycomb repressive complex 2. Chromosoma. 2012;121(3):221-34. doi:10.1007/s00412-012-0361-1.

81. Pan X, Papasani M, Hao Y, Calamito M, Wei F, Quinn Iii WJ, et al. YY1 controls IgK repertoire and B-cell development, and localizes with condensin on the IgK locus. EMBO J. 2013;32(8):1168-82. doi:10.1038/emboj.2013.66.

82. Atchison ML. Function of YY1 in long-distance DNA interactions. Front Immunol. 2014;5:45. doi:10.3389/fimmu.2014. 00045.

83. Shah PP, Donahue G, Otte GL, Capell BC, Nelson DM, Cao K, et al. Lamin B1 depletion in senescent cells triggers large-scale changes in gene expression and the chromatin landscape. Genes Dev. 2013;27(16):1787-99. doi:10.1101/gad.223834.113.

84. Towbin BD, Gonzalez-Aguilera C, Sack R, Gaidatzis D, Kalck V, Meister P, et al. Step-wise methylation of histone $\mathrm{H} 3 \mathrm{~K} 9$ positions heterochromatin at the nuclear periphery. Cell. 2012;150(5):934 47. doi:10.1016/j.cell.2012.06.051.

85. Bian Q, Khanna N, Alvikas J, Belmont AS. beta-Globin cis-elements determine differential nuclear targeting through epigenetic modifications. J Cell Biol. 2013;203(5):767-83. doi:10.1083/jcb. 201305027.

86. Gardini A, Shiekhattar R. The many faces of long noncoding RNAs. FEBS J. 2015;282(9):1647-57. doi:10.1111/febs.13101.

87. Carninci P, Kasukawa T, Katayama S, Gough J, Frith MC, Maeda $\mathrm{N}$, et al. The transcriptional landscape of the mammalian genome. Science. 2005;309(5740):1559-63.

88. Derrien T, Johnson R, Bussotti G, Tanzer A, Djebali S, Tilgner H, et al. The GENCODE v7 catalog of human long noncoding RNAs: analysis of their gene structure, evolution, and expression. Genome Res. 2012;22(9):1775-89. doi:10.1101/gr.132159.111.

89. Cabili MN, Trapnell C, Goff L, Koziol M, Tazon-Vega B, Regev A, et al. Integrative annotation of human large intergenic noncoding RNAs reveals global properties and specific subclasses. Genes Dev. 2011;25(18):1915-27. doi:10.1101/gad.17446611.

90. Ponjavic J, Ponting CP, Lunter G. Functionality or transcriptional noise? Evidence for selection within long noncoding RNAs. Genome Res. 2007;17(5):556-65. doi:10.1101/gr.6036807.

91. Sleutels F, Zwart R, Barlow DP. The non-coding Air RNA is required for silencing autosomal imprinted genes. Nature. 2002;415(6873):810-3. doi:10.1038/415810a.

92. Thakur N, Tiwari VK, Thomassin H, Pandey RR, Kanduri M, Gondor A, et al. An antisense RNA regulates the bidirectional silencing property of the Kcnq1 imprinting control region. Mol 
Cell Biol. 2004;24(18):7855-62. doi:10.1128/mcb.24.18.78557862.2004.

93. Rinn JL. Functional demarcation of active and silent chromatin domains in human HOX loci by noncoding RNAs. Cell. 2007;129:1311-23.

94. Tsai MC, Manor O, Wan Y, Mosammaparast N, Wang JK, Lan F, et al. Long noncoding RNA as modular scaffold of histone modification complexes. Science. 2010;329(5992):689-93. doi:10. 1126/science.1192002.

95. Tsai MC, Wang JK, Chang HY. Tumor suppression by the histone demethylase UTX. Cell Cycle. 2010;9(11):2043-4.

96. Hacisuleyman E, Goff LA, Trapnell C, Williams A, Henao-Mejia $\mathrm{J}$, Sun L, et al. Topological organization of multichromosomal regions by the long intergenic noncoding RNA Firre. Nat Struct Mol Biol. 2014;21(2):198-206. doi:10.1038/nsmb.2764.

97. Hasegawa Y, Brockdorff N, Kawano S, Tsutui K, Tsutui K, Nakagawa $\mathrm{S}$. The matrix protein hnRNP U is required for chromosomal localization of Xist RNA. Dev Cell. 2010;19(3):469-76. doi:10.1016/j.devcel.2010.08.006.

98. Minajigi A, Froberg JE, Wei C, Sunwoo H, Kesner B, Colognori $\mathrm{D}$ et al. Chromosomes. A comprehensive Xist interactome reveals cohesin repulsion and an RNA-directed chromosome conformation. Science. 2015; 349(6245). doi:10.1126/science.aab2276.
First evidence that ncRNAs influence the topological organization of mammalian genomes.

99. Sheardown SA, Duthie SM, Johnston CM, Newall AE, Formstone EJ, Arkell RM, et al. Stabilization of Xist RNA mediates initiation of X chromosome inactivation. Cell. 1997;91(1):99-107.

100. Sarma K, Cifuentes-Rojas C, Ergun A, Del Rosario A, Jeon Y, White F, et al. ATRX directs binding of PRC2 to Xist RNA and polycomb targets. Cell. 2014;159(4):869-83. doi:10.1016/j.cell. 2014.10.019.

101. Jeon Y, Lee JT. YY1 tethers Xist RNA to the inactive X nucleation center. Cell. 2011;146(1):119-33. doi:10.1016/j.cell.2011.06.026.

102. Misteli T. Higher-order genome organization in human disease. Cold Spring Harb Perspect Biol. 2010;2(8):a000794. doi:10. 1101/cshperspect.a000794.

103. Rousseau M, Ferraiuolo MA, Crutchley JL, Wang XQ, Miura H, Blanchette $\mathrm{M}$, et al. Classifying leukemia types with chromatin conformation data. Genome Biol. 2014;15(4):R60. doi:10.1186/ gb-2014-15-4-r60. First evidence that chromatin conformation can be used to classify human disease.

104. Crutchley JL, Wang XQ, Ferraiuolo MA, Dostie J. Chromatin conformation signatures: ideal human disease biomarkers? Biomark Med. 2010;4(4):611-29. doi:10.2217/bmm.10.68. 